\title{
Further thoughts on the taxonomy and vector role of Rhipicephalus sanguineus group ticks
}

\author{
Filipe Dantas-Torres ${ }^{\mathrm{a}, \mathrm{b}, *}$, Domenico Otranto ${ }^{\mathrm{b}}$ \\ a Department of Immunology, Aggeu Magalhães Research Centre, Oswaldo Cruz Foundation, 50670420 Recife, PE, Brazil \\ b Department of Veterinary Medicine, University of Bari, 70010 Valenzano, Bari, Italy
}

\section{A R T I C L E I N F O}

\section{Keywords:}

Rhipicephalus sanguineus

Ticks

Taxonomy

Genetics

Morphology

Pathogens

\begin{abstract}
A B S T R A C T
Rhipicephalus sanguineus is a tick species described in 1806 by Latreille, based on specimens probably collected in France. However, this is a taxon with uncertain morphological definition and recent studies have gathered irrefutable evidence supporting the existence of a cryptic species-complex under the name ' $R$. sanguineus', whose number of sibling species around the world has yet to be ascertained. This fact is of great medical and veterinary concern, also considering that ticks currently identified as ' $R$. sanguineus' have been regarded as proven or putative vectors of several pathogens infecting dogs and humans. Differences in the distribution and prevalence of some of these microorganisms (e.g., Ehrlichia canis and Hepatozoon canis) further support the existence of distinct species under the name ' $R$. sanguineus' and suggest that the vector competence of these tick species may vary. This article provides an account on the taxonomy and the vector role of ticks belonging to the $R$. sanguineus group in the light of recent research.
\end{abstract}

(C) 2014 Elsevier B.V. All rights reserved.

\section{Introduction}

Rhipicephalus sanguineus sensu stricto (s.s.) was originally described in 1806 as Ixodes sanguineus (Latreille, 1806). While its description was accepted for that time, when tick taxonomy was still in its infancy, it was a rather poor, incomplete description, as follows: "Sanguineus, punctatus, postice lineolis tribus impressus; dorso antico macula nulla thoracica, distincta" (Latreille, 1806); that is, "blood red, punctate, posteriorly with three impressed lines; no distinct 'thoracic' spot anterodorsally". Furthermore, Latreille provided almost no detail regarding the type specimen of the so-called 'I. sanguineus', being the only

\footnotetext{
* Corresponding author at: Aggeu Magalhães Research Centre, Department of Immunology, Oswaldo Cruz Foundation, 50670420 Recife, PE, Brazil. Tel.: +55 81 21012551; fax: +55 8121012551.

E-mail address: filipe.vet@globo.com (F. Dantas-Torres).
}

information provided "habitat in Gallia" (Latreille, 1806). Indeed, Gallia is the Latin name given by the Romans to the territories where the Celtic Gauls lived in the Iron Age and the Roman period (circa from the 5 th century BC to the 3rd century AD). As a matter of fact, Gallia included present-day France, Belgium, Luxemburg and parts of the Netherlands, Switzerland, Germany on the west bank of the Rhine, and the Po Valley (Arrowsmith, 1832). Nonetheless, most tick taxonomists agree that the type locality of $R$. sanguineus s.s. is in France (Nava et al., 2012).

Subsequently, several renowned tick taxonomists (N. A. Filippova, H. Hoogstraal, I. G. Horak, C. L. Koch, P. C. Morel, L. G. Neumann, J. B. Walker and F. Zumpt, to name but a few) endeavoured to produce reliable keys and/or morphological accounts for $R$. sanguineus s.s. and related species (e.g., Koch, 1844; Neumann, 1911; Morel and Vassiliades, 1963; Filippova, 1997; Walker et al., 2000). The most recent redescription available for this species may be found in "The genus Rhipicephalus (Acari, Ixodidae): a guide to the brown 
ticks of the world", a reference textbook for Rhipicephalus ticks (Walker et al., 2000). Nonetheless, these morphological accounts are not reliable because they were based on specimens collected in different continents and may actually represent different species.

The name ' $R$. sanguineus' is supported by its usage and it was considered as a valid species in several world lists of tick names (Camicas et al., 1998; Horak et al., 2002; Barker and Murrell, 2004; Guglielmone et al., 2010, 2014; Guglielmone and Nava, 2014). However, results from several crossbreeding and genetic studies (Bernasconi et al., 2002; Szabó et al., 2005; Burlini et al., 2010; Moraes-Filho et al., 2011; Levin et al., 2012; Nava et al., 2012; Liu et al., 2013; Dantas-Torres et al., 2013) suggested that ticks currently identified as ' $R$. sanguineus' actually include a group of sibling species. Indeed, the most recent world list of tick names (Guglielmone et al., 2014) considered that besides Gallia (type locality), records of $R$. sanguineus s.s. from around the world are currently considered speculative, as they represent a yet unknown number of valid species $(R$. sanguineus sensu lato). Nonetheless, even ticks collected from dogs in France should be at present referred to as $R$. sanguineus s.l., since genetically distinct populations of ticks have been reported to occur in this country (DantasTorres et al., 2013).

In recent years, several aspects related to the taxonomy, biology, ecology, and vector role of $R$. sanguineus s.l. have been reviewed in the international literature (DantasTorres, 2008, 2010; Gray et al., 2013). This article provides an account on the taxonomy and the vector role of ticks belonging to the $R$. sanguineus group in the light of recent research.

\section{The Rhipicephalus sanguineus group}

For quite some time, the $R$. sanguineus group has been subject to considerable debate among taxonomists from around the world (Zahler et al., 1997). Camicas et al. (1998) listed 17 species for this group (Table 1 ).

While some ticks belonging to this group are fairly different from a morphological perspective, some of them are similar and difficult to identify on morphological grounds alone. For instance, $R$. pusillus is very distinct morphologically and also genetically from some species belonging to the $R$. sanguineus group (Zahler et al., 1997). Indeed, a more profound assessment of its affiliation to the $R$. sanguineus group has been encouraged (Zahler et al., 1997). As another example, $R$. rossicus is quite similar morphologically, and genetically very close, to $R$. pumilio and it has been suggested that they may be conspecific (Zahler et al., 1997) or, perhaps, subspecies (Beati and Keirans, 2001).

The core problem of this group is perhaps the absence of a morphological definition for $R$. sanguineus s.s. In particular, this tick has long been confounded with $R$. turanicus (and vice versa). Pegram et al. (1987) attempted to clarify the status of this species, but it is uncertain whether bona fide $R$. turanicus specimens were involved in their work, as emphasized by Guglielmone and Nava (2014). Later on, Filippova (1997) re-described $R$. turanicus and provided a bona fide morphological definition for the species. Genetic data for $R$. turanicus collected by flagging in Turkmenistan
Table 1

Species of the Rhipicephalus sanguineus group (sensu Camicas et al., 1998).

\begin{tabular}{l}
\hline Species and authorities \\
\hline Rhipicephalus aurantiacus (Neumann, 1907) \\
Rhipicephalus bergeoni (Morel and Balis, 1976) \\
Rhipicephalus boueti (Morel, 1957) \\
Rhipicephalus camicasi (Morel, Mouchet and \\
Rodhain, 1976) \\
Rhipicephalus guilhoni (Morel and Vassiliades, \\
1963) \\
Rhipicephalus leporis (Pomerantzev, 1946) \\
Rhipicephalus moucheti (Morel, 1965) \\
Rhipicephalus pumilio (Schulze, 1935) \\
Rhipicephalus pusillus (Gil Collado, 1936) \\
Rhipicephalus ramachandrai (Dhanda, 1966) \\
Rhipicephalus rossicus (Yakimov and \\
Kol-Yakimova, 1911) \\
Rhipicephalus sanguineus (Latreille, 1806) \\
Rhipicephalus schulzei (Olenev, 1929) \\
Rhipicephalus sulcatus (Neumann, 1908) \\
Rhipicephalus tetracornus (Kitaoka and Suzuki, \\
1983) \\
Rhipicephalus turanicus (Pomerantzev, 1940)
\end{tabular}

Geographical

distribution

Afro-tropical Afro-tropical Afro-tropical Afro-tropical, Palearctic

Afro-tropical

Palearctic Afro-tropical Palearctic Palearctic Oriental Palearctic

Cosmopolitan $^{\mathrm{a}}$ Palearctic Afro-tropical Oriental

Afro-tropical, Oriental, Palearctic Afro-tropical

Rhipicephalus ziemanni (Neumann, 1904) ${ }^{a} R$. sanguineus has long been considered to be a cosmopolitan tick
species, but this is a taxon with uncertain morphological definition and therefore, its geographical distribution is uncertain as well.

and identified by Filippova is now available in GenBank (KF145150.1 for 16S, KF145151.1 for 12S and KF145152.1 and KF145153.1 for cox1) (Dantas-Torres et al., 2013). However, in the absence of a morphological definition and specific genetic markers for $R$. sanguineus s.s., its precise discrimination with $R$. turanicus is still a difficult task.

In addition to the lack of a morphological definition for $R$. sanguineus S.S., recent genetic studies assessing the variability of ticks collected from dogs in different continents were consistent in demonstrating the existence of two well distinct populations under the name ' $R$. sanguineus' (Szabó et al., 2005; Burlini et al., 2010; Moraes-Filho et al., 2011; Levin et al., 2012; Nava et al., 2012; Dantas-Torres et al., 2013; Liu et al., 2013). For example, an analysis of mitochondrial 16S rDNA sequences from $R$. sanguineus s.l. collected in 29 localities of nine Latin American countries with those from South Africa, Spain, and Italy revealed the existence of two main phylogenetic clades and six different haplotypes (Moraes-Filho et al., 2011). One clade included three haplotypes $(\mathrm{A}-\mathrm{C})$ from Latin America related to ticks from South Africa, which were all designated as the 'tropical' species. The other group included the three remaining haplotypes (D-F) from Latin America, which were related to ticks from Europe and designated as the 'temperate' species. As a corollary, another investigation also suggested the existence of two main groups, one including haplotypes from localities of Argentina, Uruguay and Chile (namely, the 'Southern' linage) and other clustering haplotypes from Brazil, Paraguay, Colombia, South Africa, Mozambique, and from two localities of Northern Argentina (the 'Northern' linage) (Nava et al., 2012). The authors concluded that ticks from the Northern linage and from Mozambique and South Africa represent a single species that is not $R$. sanguineus s.s., 
Table 2

Pathogens transmitted by Rhipicephalus sanguineus sensu lato to dogs and humans (Dantas-Torres, 2008; Dantas-Torres et al., 2012b).

\begin{tabular}{lll}
\hline Pathogen & Disease name & $\begin{array}{l}\text { Zoonotic } \\
\text { potential }\end{array}$ \\
\hline $\begin{array}{c}\text { Acanthocheilonema } \\
\text { dracunculoides } \\
\text { Anaplasma platys }\end{array}$ & Subcutaneous filariosis & No \\
& $\begin{array}{l}\text { Infectious canine cyclic } \\
\text { thrombocytopenia }\end{array}$ & Yes \\
Babesia gibsoni & Babesiosis & No \\
Babesia vogeli & Babesiosis & No \\
Cercopithifilaria bainae & Subcutaneous filariosis & No \\
Cercopithifilaria grassi & Subcutaneous filariosis & No \\
Coxiella burnetii & Q fever & Yes \\
Ehrlichia canis & Monocytic ehrlichiosis & Yes \\
Hepatozoon canis & Hepatozoonosis & No \\
Leishmania infantum & Visceral leishmaniosis & Yes \\
Mycoplasma & Haemobartonellosis & No \\
haemocanis & & \\
Rickettsia conorii & Mediterranean spotted & Yes \\
& fever (Boutonneuse & \\
fickettsia massiliae & fever) & \\
Rickettsia rickettsii & Spotted-fever & Yes \\
& spotted fever & Yes \\
\hline
\end{tabular}

whereas ticks from the Southern linage and from Western Europe probably represent the true $R$. sanguineus s.s.

Additional research has shed more light on the matter. We examined ticks collected in 17 countries and assessed their genetic variability using three genetic markers (i.e., 16S rDNA, 12S rDNA, and cox1). Results from this study showed that in addition to the two previously characterized lineages of $R$. sanguineus s.l., dogs may be infested by other tick species, including $R$. turanicus and two morphologically and genetically distinct lineages of ticks designated as Rhipicephalus sp. I and Rhipicephalus sp. III (Dantas-Torres et al., 2013). The so-called tropical species (=northern lineage) is present in all continents and it forms a sister group with $R$. guilhoni. Finally, a more recent study also revealed that $R$. rossicus is the predominant species found on dogs in the steppe region of south-eastern Romania (Dumitrache et al., 2014). Altogether, these studies indicate that the situation in the Old World is much more complicated than in the New World, where tropical and temperate lineages of $R$. sanguineus s.l. are apparently the only representatives of the $R$. sanguineus group found on dogs.

\section{Rhipicephalus sanguineus group and associated pathogens}

With some exceptions, there is little information regarding the vector role of ticks belonging to the $R$. sanguineus group. Ticks identified as $R$. sanguineus s.l. have been regarded as proven or putative vectors for a number of pathogenic microorganisms, including bacteria, protozoa, and nematodes (Table 2). Most of these pathogens have been implicated as causative agents of diseases in dogs, but some of them may also infect humans (reviewed in Dantas-Torres et al., 2012b).

Studies carried out in different parts of the world suggest that there might be differences in terms of vector competence among populations (or sibling species) of $R$. sanguineus s.l. In October 2009, an outbreak of canine hepatozoonosis was reported in a confined dog population in southern Italy and a high prevalence of Hepatozoon canis infection was recorded in engorged nymphs of Rhipicephalus sp. I collected from the immediate environment where the dogs lived (Dantas-Torres et al., 2012a). A subsequent laboratory study demonstrated the transstadial transmission of $\mathrm{H}$. canis from larvae to nymphs of Rhipicephalus sp. I (Giannelli et al., 2013). These findings suggested a high transmission efficiency for this tick population of southern Italy designated as Rhipicephalus sp. I. On the other hand, evidence from Brazil indicates that the tropical lineage of $R$. sanguineus s.l. may not be a vector of $H$. canis (Demoner et al., 2013). Indeed, a recent study molecularly assessed the presence of $H$. canis in 81 ticks from around the world belonging to the tropical lineage of $R$. sanguineus s.l. and none of them was positive (Latrofa et al., 2014). In contrast, ticks belonging to the temperate lineage of $R$. sanguineus s.l. as well as ticks identified as Rhipicephalus sp. I and Rhipicephalus sp. III were found positive. Altogether, the aforementioned studies indicate the existence of distinct populations (or sibling species) of $R$. sanguineus s.l. around the world whose vector competence for H. canis may vary.

Cases of apparent tick paralysis were reported in the same animal shelter in southern Italy where the outbreak of canine hepatozoonosis was detected, and the so-called Rhipicephalus sp. I was the only tick found on dogs (Otranto et al., 2012a). Incidentally, cases of tick paralysis in dogs have usually been associated with other tick species (e.g., Ixodes holocyclus) (Webster et al., 2013) and only a single case was attributed to ' $R$. sanguineus' in a dog from Venezuela (Viloria, 1954). The possible occurrence of such an outbreak of tick paralysis (Otranto et al., 2012a) would suggest a higher capacity of inducing toxicosis for this tick population present in southern Italy (i.e., Rhipicephalus sp. I), and raises questions as to whether genetically distinct $R$. sanguineus s.l. populations may differ in their capability to induce toxicosis in dogs.

Variations in terms of vector competence also seem to occur with other pathogens. For example, studies conducted in Uruguay and Japan investigated the occurrence of Ehrlichia canis infection in $R$. sanguineus s.l. ticks collected on dogs in urban and suburban areas but all ticks tested were negative (Inokuma et al., 2003; Venzal et al., 2007). Conversely, $R$. sanguineus s.l. ticks collected from dogs in several other countries have been found naturally infected with E. canis (Murphy et al., 1998; Ybañez et al., 2012). It is worth mentioning that the pathogen infection rate in ticks also depends on the methods used for their detection, feeding status of ticks, period of the year ticks were collected, infectious status of dogs, and number of ticks tested. A study conducted in Brazil reported E. canis infection rates ranging from 0 to $6.2 \%$ in $R$. sanguineus s.l. from different localities (Aguiar et al., 2007). Remarkably, a recent experimental study investigated the competence of four South American populations of $R$. sanguineus s.l. in transmitting E. canis to dogs and provided evidence indicating that while ticks from south-eastern Brazil were competent vectors of E. canis, those from Argentina, Uruguay and south of Brazil were not (Moraes-Filho et al., 2012). Furthermore, 
although traditionally associated to disease in dogs, E. canis has been implicated in cases of ehrlichiosis in humans in Venezuela (Perez et al., 2006). It remains to be clarified whether the Venezuelan population of $R$. sanguineus s.l. is more attracted to humans than other Latin American populations (Dantas-Torres et al., 2006).

Another key example is represented by Anaplasma platys, a rickettsial agent that infects the platelets of dogs worldwide. An experimental study failed to demonstrate that a North American strain of $R$. sanguineus s.l. is able to transmit A. platys (Simpson et al., 1991). However, circumstantial evidence indicates that $A$. platys may be transmitted by $R$. sanguineus s.l. (Inokuma et al., 2000; Sanogo et al., 2003). For example, a recent study suggested Rhipicephalus sp. I as a putative vector for A. platys in southern Italy (Ramos et al., 2013). Once again, these findings suggest that there might be some strain- or populationrelated differences in terms of vector competence of $R$. sanguineus s.l. ticks for $A$. platys.

\section{Concluding remarks and perspectives}

The vast geographical distribution of $R$. sanguineus s.l. ticks may be attributed to its adaptability to different climate conditions and to their close association with the domestic dog, with which they have travelled around the world. However, evidence indicates that some ticks identified as ' $R$. sanguineus' around the world actually belong to different species that have long been overlooked by tick taxonomists, probably due to the lack of a bona fide morphological definition for $R$. sanguineus s.s.

Rhipicephalus has long been considered a problematic genus (Hoogstraal, 1956), due to the morphological similarities among closely related species as well as due to the intraspecific variations within populations of the same species. Particularly, the taxonomy of $R$. sanguineus s.s. and some closely related species is still an issue of ongoing debate. Neumann, for example, divided this species into three subspecies: $R$. sanguineus sanguineus, $R$. sanguineus punctatissimus, and $R$. sanguineus brevicollis (Neumann, 1911). These subspecies have been regarded as incertae sedis in Guglielmone and Nava (2014).

Recent morphological and phylogenetic studies have added weight to the hypothesis on the existence of a cryptic species-complex under the name ' $R$. sanguineus'. Only a consensual definition of $R$. sanguineus s.s., based on both morphological and genetic data, will allow taxonomists to assess the validity of other species belonging to this group, through the re-examination of type specimens available in reference collection as well as through the collection and examination of new tick material collected in type localities.

Beyond taxonomy, a better definition of the so-called $R$. sanguineus group will be fundamental for the understanding of the transmission pattern and distribution of several tick-borne diseases of dogs and humans, such as Mediterranean spotted fever and Rocky Mountain spotted fever, as well as for predicting the emergence of new zoonotic pathogens (e.g., E. canis in Venezuela). Moreover, it remains to be addressed whether the interaction of $R$. sanguineus s.l. with different host species has influenced the encounter and the adaptation of this tick to different pathogens.

Several attempts have been made to find better criteria for species definition in the genus Rhipicephalus. We endorse the words of Hoogstraal, who nearly half a century ago stated that "problems of morphological and biological criteria for this genus are not likely to be solved until more exhaustive field research and patient laboratory investigation have been devoted to them" (Hoogstraal, 1956).

\section{Conflict of interest statement}

The authors declare that they have no conflict of interests.

\section{Acknowledgments}

The authors thank Rafael Ramos do Nascimento Santos (University of Bari, Italy) for his assistance during the manuscript preparation. Some data presented in this manuscript were generated in researches partially supported by Bayer Animal Health (Germany).

\section{References}

Arrowsmith, A., 1832. A Grammar of Ancient Geography: Compiled for the Use of King's College School. Hansard, London, pp. 329pp.

Aguiar, D.M., Cavalcante, G.T., Pinter, A., Gennari, S.M., Camargo, L.M., Labruna, M.B., 2007. Prevalence of Ehrlichia canis (Rickettsiales: Anaplasmataceae) in dogs and Rhipicephalus sanguineus (Acari: Ixodidae) ticks from Brazil. J. Med. Entomol. 44, 126-132.

Barker, S.C., Murrell, A., 2004. Systematics and evolution of ticks with a list of valid genus and species names. Parasitology 129, S15-S36.

Beati, L., Keirans, J.E., 2001. Analysis of the systematic relationships among ticks of the genera Rhipicephalus and Boophilus (Acari: Ixodidae) based on mitochondrial 12S ribosomal DNA gene sequences and morphological characters. J. Parasitol. 87, 32-48.

Bernasconi, M.V., Casati, S., Peter, O., Piffaretti, J.C., 2002. Rhipicephalus ticks infected with Rickettsia and Coxiella in Southern Switzerland (Canton Ticino). Infect. Genet. Evol. 2, 111-120.

Burlini, L., Teixeira, K.R., Szabó, M.P., Famadas, K.M., 2010. Molecular dissimilarities of Rhipicephalus sanguineus (Acari: Ixodidae) in Brazil and its relation with samples throughout the world: is there a geographical pattern? Exp. Appl. Acarol. 50, 361-374.

Camicas, J.L., Hervy, J.P., Adam, F., Morel, P.C., 1998. Les tiques du monde. Nomenclature, stades décrits, hôtes, repartition (Acarida, Ixodida). Orstom, Paris, pp. 233 pp.

Dantas-Torres, F., Figueredo, L.A., Brandão-Filho, S.P., 2006. Rhipicephalus sanguineus (Acari: Ixodidae), the brown dog tick, parasitizing humans in Brazil. Rev. Soc. Bras. Med. Trop. 39, 64-67.

Dantas-Torres, F., Latrofa, M.S., Weigl, S., Tarallo, V.D., Lia, R.P., Otranto, D., 2012a. Hepatozoon canis infection in ticks during spring and summer in Italy. Parasitol. Res. 110, 695-698.

Dantas-Torres, F., Chomel, B.B., Otranto, D., 2012b. Ticks and tick-borne diseases: a One Health perspective. Trends Parasitol. 28, 437-446.

Dantas-Torres, F., Latrofa, M.S., Annoscia, G., Giannelli, A., Parisi, A., Otranto, D., 2013. Morphological and genetic diversity of Rhipicephalus sanguineus sensu lato from the new and old worlds. Parasites Vectors $6,213$.

Dantas-Torres, F., 2008. The brown dog tick, Rhipicephalus sanguineus (Latreille, 1806) (Acari: Ixodidae): from taxonomy to control. Vet. Parasitol. 152, 173-185.

Dantas-Torres, F., 2010. Biology and ecology of the brown dog tick, Rhipicephalus sanguineus. Parasites Vectors 3, 26.

Demoner, L.C., Rubini, A.S., Paduan, K.S., Metzger, B., de Paula Antunes, J.M., Martins, T.F., Mathias, M.I., O'Dwyer, L.H., 2013. Investigation of tick vectors of Hepatozoon canis in Brazil. Ticks Tick Borne Dis. 4, 542-546.

Dumitrache, M.O., Kiss, B., Dantas-Torres, F., Latrofa, M.S., D’Amico, G., Sándor, A.D., Mihalca, A.D., 2014. Seasonal dynamics of Rhipicephalus rossicus attacking domestic dogs from the steppic region of southeastern Romania. Parasites Vectors 7, 97. 
Filippova, N.A., 1997. Fauna of Russia and Neighbouring Countries. Ixodid Ticks of Subfamily Amblyomminae. Nauka Publishing House, Moscow, Russia, pp. 436pp.

Giannelli, A., Ramos, R.A., Di Paola, G., Dantas-Torres, F., Baneth, G., Otranto, D., 2013. Transstadial transmission of Hepatozoon canis from larvae to nymphs of Rhipicephalus sanguineus. Vet. Parasitol. 196, 1-5.

Gray, J., Dantas-Torres, F., Estrada-Peña, A., Levin, M., 2013. Systematics and ecology of the brown dog tick, Rhipicephalus sanguineus. Ticks Tick Borne Dis. 4, 171-180.

Guglielmone, A.A., Nava, S., 2014. Names for Ixodidae (Acari: Ixodoidea): valid, synonyms, incertae sedis, nomina dubia, nomina nuda, lapsus, incorrect and suppressed names-with notes on confusions and misidentifications. Zootaxa 3767, 1-256.

Guglielmone, A.A., Robbins, R.G., Apanaskevich, D.A., Petney, T.N., EstradaPeña, A., Horak, I.G., Shao, R., Barker, S.C., 2010. The Argasidae. Ixodidae and Nuttalliellidae (Acari: Ixodida) of the world: a list of valid species names. Zootaxa 2528, 1-28.

Guglielmone, A.A., Robbins, R.G., Apanaskevich, D.A., Petney, T.N., EstradaPeña, A., Horak, I.G., 2014. The Hard Ticks of the World. (Acari: Ixodida: Ixodidae). Springer, Dordrecht, Heidelberg, New York, London, pp. 738pp.

Hoogstraal, H., 1956. African Ixodoidea I: Ticks of the Sudan (with Special Reference to Equatoria Province and with Preliminary Reviews of the Genera Boophilus, Margaropus, and Hyalomma). Dept. of the Navy, Bureau of Medicine and Surgery, Washington, DC, 1101 pp.

Horak, I.G., Camicas, J.L., Keirans, J.E., 2002. The Argasidae, Ixodidae and Nuttalliellidae (Acari: Ixodida): a world list of valid tick names. Exp. Appl. Acarol. 28, 27-54.

Inokuma, H., Raoult, D., Brouqui, P., 2000. Detection of Ehrlichia platys DNA in brown dog ticks (Rhipicephalus sanguineus) in Okinawa Island, Japan. J. Clin. Microbiol. 38, 4219-4221.

Inokuma, H., Beppu, T., Okuda, M., Shimada, Y., Sakata, Y., 2003. Epidemiological survey of Anaplasma platys and Ehrlichia canis using ticks collected from dogs in Japan. Vet. Parasitol. 115, 343-348.

Koch, C.L., 1844. Systematische übersicht über die Ordung der Zecken. Archiv. für Naturgeschichte 10, 217-239.

Latreille, P.A., 1806. Genera crustaceorum et insectorum secundum ordinem naturalem in familia disposita, iconibus exemplisque plurimis explicata. Parisiis et Argentorati, apud Amand Koenig, Paris, $302 \mathrm{pp}$.

Latrofa, M.S., Dantas-Torres, F., Giannelli, A., Otranto, D., 2014. Molecular detection of tick-borne pathogens in Rhipicephalus sanguineus group ticks. Ticks Tick Borne Dis. 5, 943-946.

Levin, M.L., Studer, E., Killmaster, L., Zemtsova, G., Mumcuoglu, K.Y., 2012. Crossbreeding between different geographical populations of the brown dog tick, Rhipicephalus sanguineus (Acari: Ixodidae). Exp. Appl. Acarol. 58, 51-68.

Liu, G.-H., Chen, F., Chen, Y.-Z., Song, H.-Q., Lin, R.-Q., Zhuo, D.-H., Zhu, X.-Q., 2013. Complete mitochondrial genome sequence data provides genetic evidence that the brown dog tick Rhipicephalus sanguineus (Acari: Ixodidae) represents a species complex. Int. J. Biol. Sci. 9, 361-369.

Moraes-Filho, J., Marcili, A., Nieri-Bastos, F.A., Richtzenhain, L.J., Labruna, M.B., 2011. Genetic analysis of ticks belonging to the Rhipicephalus sanguineus group in Latin America. Acta Trop. 117, 51-55.

Moraes-Filho, J., Soares, J.F., Labruna, M.B., 2012. Study on the Vector competence for Ehrlichia canis of four Neotropical populations of Rhipicephalus sanguineus. In: FAMERP-UTMB: Emerging Infections in the Americas? Common Interests and Collaboration Between Brazil and USA. Sociedade de Medicina e Cirurgia, São José do Rio Preto, Brazil.

Morel, P.-C., Vassiliades, G., 1963. Les Rhipicephalus du groupe sanguineus: espèces Africaines (Acariens: Ixodoidea). Rev. Élev. Méd. Vét. Pays Trop. 15, 343-386.

Murphy, G.L., Ewing, S.A., Whitworth, L.C., Fox, J.C., Kocan, A.A., 1998. A molecular and serologic survey of Ehrlichia canis, E. chaffeensis, and E. ewingii in dogs and ticks from Oklahoma. Vet. Parasitol. 79, 325-339.

Nava, S., Mastropaolo, M., Venzal, J.M., Mangold, A.J., Guglielmone, A.A., 2012. Mitochondrial DNA analysis of Rhipicephalus sanguineus sensu lato (Acari: Ixodidae) in the Southern Cone of South America. Vet. Parasitol. 190, 547-555.

Neumann, L.G., 1911. Ixodidae. Das Tierreich, Berlin, 169pp.

Otranto, D., Dantas-Torres, F., Tarallo, V.D., Ramos, R.A., Stanneck, D., Baneth, G., de Caprariis, D., 2012a. Apparent tick paralysis by Rhipicephalus sanguineus (Acari: Ixodidae) in dogs. Vet. Parasitol. 188, 325-329.

Pegram, R.G., Keirans, J.E., Clifford, C.M., Walker, J.B., 1987. Clarification of the Rhipicephalus sanguineus group (Acari, Ixodoidea, Ixodidae). II. R. sanguineus (Latreille, 1806) and related species. Syst. Parasitol. 10, 27-44.

Perez, M., Bodor, M., Zhang, C., Xiong, Q., Rikihisa, Y., 2006. Human infection with Ehrlichia canis accompanied by clinical signs in Venezuela. Ann. N.Y. Acad. Sci. 1078, 110-117.

Ramos, R.A., Giannelli, A., Dantas-Torres, F., Otranto, D., 2013. Effect of egg clustering on the fitness of Rhipicephalus sanguineus larvae. Parasitol. Res. 112, 1795-1797.

Sanogo, Y.O., Davoust, B., Inokuma, H., Camicas, J.L., Parola, P., Brouqui, P., 2003. First evidence of Anaplasma platys in Rhipicephalus sanguineus (Acari: Ixodida) collected from dogs in Africa. Onderstepoort J. Vet. Res. 70, 205-212.

Simpson, R.M., Gaunt, S.D., Hair, J.A., Kocan, K.M., Henk, W.G., Casey, H.W., 1991. Evaluation of Rhipicephalus sanguineus as a potential biologic vector of Ehrlichia platys. Am. J. Vet. Res. 52, 1537-1541.

Szabó, M.P., Mangold, A.J., João, C.F., Bechara, G.H., Guglielmone, A.A., 2005. Biological and DNA evidence of two dissimilar populations of the Rhipicephalus sanguineus tick group (Acari: Ixodidae) in South America. Vet. Parasitol. 130, 131-140.

Venzal, J.M., Estrada-Peña, A., Castro, O., De Souza, C.G., Portillo, A., Oteo, J.A., 2007. Study on seasonal activity in dogs and ehrlichial infection in Rhipicephalus sanguineus (Latreille, 1806) (Acari: Ixodidae) from southern Uruguay. Parasitol. Latinoam. 62, 23-26.

Viloria, P.R., 1954. Paralisis por garrapatos en caninos. Rev. Med. Vet. Parasitol. 13, 66-70.

Walker, J.B., Keirans, J.E., Horak, I.G., 2000. The genus Rhipicephalus (Acari, Ixodidae). In: A Guide to the Brown Ticks of the World. Cambridge University Press, Cambridge, UK, pp. 655pp.

Webster, R.A., Mills, P.C., Morton, J.M., 2013. Indications, durations and outcomes of mechanical ventilation in dogs and cats with tick paralysis caused by Ixodes holocyclus: 61 cases (2008-2011). Aust. Vet. J. 91, 229-233.

Ybañez, A.P., Perez, Z.O., Gabotero, S.R., Yandug, R.T., Kotaro, M., Inokuma, H., 2012. First molecular detection of Ehrlichia canis and Anaplasma platys in ticks from dogs in Cebu, Philippines. Ticks Tick Borne Dis. 3, 288-293.

Zahler, M., Filippova, N.A., Morel, P.-C., Gothe, R., Rinders, H., 1997. Relationship between species of the Rhipicephalus sanguineus group: a molecular approach. J. Parasitol. 82, 302-306. 